\title{
Stabilisation of the spine affected by malignancy
}

\author{
JOHN MILES, AJ BANKS, E DERVIN, Z NOORI \\ From the Associated Unit of Neurosciences, Walton Hospital, Liverpool, Bolton General Hospital, Bolton, \\ the Department of Aeronautical and Mechanical Engineering, Salford University, Manchester, and the Pain \\ Relief Foundation, Walton Hospital, Liverpool, UK
}

SUMMARY A technique for securely stabilising the spine affected by malignancy has been developed. It provides excellent pain relief and some improvement of neurological deficit, and allows of laminectomy and radiotherapy. Although the technique is relatively simple, and the materials used are commonplace and inexpensive, it needs to be learnt which may mean that surgery for spinal malignancy will need the service of a trained surgeon, rather than that of an initiate.

Patients present for acute neurosurgical admission with a provisional diagnosis of cord or cauda equina deficit due to metastatic malignancy with depressing frequency. In orthopaedic practice they constitute a major problem of differentiation from those with other forms of back pains. In oncological or combined surgical/radiotherapeutic clinics, the possibility that pain with neurological deficit indicates extension of the known disease, is a constant threat.

The incidence of spinal metastases in the population as a whole is unrecorded. The instance of spinal metastases in the group of patients with a particular primary cancer appears not be be retrievable from the wealth of hospital data currently collected. The International Classification of Diseases feeds the confusion by the undoubted ambiguity that exists in coding metastases of the brain and spine, that is, the central nervous system, and those of the bony skull and spine. During 1982, in the Mersey Regional Department of Medical and Surgical Neurology, 26 operations were undertaken for malignancy of the spine. All but three were for metastases. At least five patients were admitted with confirmed metastases, but not operated upon, usually on the grounds of general debility. Another five patients were referred, but not admitted. Therefore in excess of 33 patients presented for neurosurgery from a population of nearly $3 \cdot 2$ million $(1: 100,000)$. In our associated general hospital, Walton Hospital, during the

Address for reprint requests: Mr John Miles, Walton Hospital, Rice Lane, Liverpool, L9 1AE, UK

Received 6 January 1984

Accepted 23 February 1984 same year, a further 14 patients had diagnosed metastases of the spine and came from a local population of 268,000 . These did not come to neurosurgery. If there was equal access and referral to neurosurgery, from all parts of our region (almost certainly not the case), then around 150 patients within our region will have metastases of the spine and do not come to neurosurgery. Clearly the condition constitutes a significant problem.

The relative incidence of particular types of cancer amongst all those presenting with metastases of the spine to a general hospital has been determined.' ${ }^{\prime}$ Cancer of the lung is commonest (33\%) followed by that from the breast cancer $(28 \%)$. Twenty-five percent are made up of various other cancers and an average of $14 \%$ have no known primary source.

In general the results of all treatment are poor. Specifically, in neurosurgical practice, there appears little room for optimism. Most commonly when the diagnosis is unequivocal, efforts are directed towards avoiding intervention. In practice this usually means arranging urgent radiotherapy. When the diagnosis is not known, intervention is directed to establishing this and exctuding the small number of relatively more favourable conditions such as myeloma or prostatic cancer. Unsuspected benign conditions like disc protrusion must be even more unlikely. Whether urgent transfer for radiotherapy, or more commonly expedious transfer back to the referring physicians is arranged, there is usually no attempt to initiate and maintain mobilisation. There is usually little awareness of the short term rehabilitation achieved or the longterm outcome.

The assessment of current treatment by Hensen 
and Urich ${ }^{2}$ is a true reflection of the pessimism: "Viewed dispassionately, it seems unlikely that the results of treatment could be much worse if radiotherapy alone was employed in all cases... there is scope for useful further clinical comparison of the results of surgery and radiotherapy."

\section{The clinical syndrome}

Pain, locally, or radiating in a radiculopathic manner is commonly the prominent symptom being present in more than $90 \%$ of cases. ${ }^{3}$ When metastases are the cause, the pain usually precedes neurological abnormality by two to three months. Although necropsy studies have shown that metastases are equally distributed throughout the vertebral column, ${ }^{4}$ presentation in two thirds is due to the thoracic deposits and pain is localised to the interscapular region. ${ }^{5}$ The pain maybe constant, boring, and occurring at night, as is so common with cancer pains and is presumably due to periosteal distortion. However, it is often worse on weight bearing, twisting and bending and relieved by lying down or keeping still. Rarely there is sudden exacerbation of pain during movement, the result of acute vertebral collapse.

The neurological syndrome, be it either myelopathic or radiculopathic, of the cauda equina or cervical roots, evolves relatively rapidly, often over days or weeks. That due to prostatic deposits or myeloma can take months. Primary spinal malignancy tends to be slower in its evolution, again taking months. Acute vertebral collapse can precipitate neurological deterioration within hours, but is uncommon.

Primary malignancy of the spine, although much less frequent and usually involving a more protracted course, generates the same problems and suffers from the same lack of success. Cordoma is probably the most common primary tumour of the spine, and while this may be considered a congenital tumour of cell rests with an expected indolent course, it sometimes has a surprisingly rapid growth which cannot be controlled even by repeated local resection. Some are frankly malignant and metastatise. ${ }^{6}$ Various forms of sarcoma are the next most common primary tumours of the spine.

\section{Current management}

If the diagnosis is known, any remaining possibility of suppressing the primary disease, will often indicate the first line of treatment. This may be endocrinological ${ }^{7}$ directed to the ovaries in carcinomatosis from the breast, or the testes in that from the pros- tate or to the pituitary gland in either case. Cytotoxic therapy may be appropriate ${ }^{8}$ In practice radiotherapy is most commonly employed and there is no doubt that it can be effective and is relatively undisturbing. It is generally considered that radiotherapy is the best form of treatment for pain due to spinal metastases. ${ }^{2}$ We know of no comparative trial confirming this.

If neurological deficit is present, there is no doubt that some form of decompression is to be preferred before radiotherapy because irradiation might result in some tumour swelling and aggravation of the neurological compression. ${ }^{9}$ If the tumour is entirely within the extradural space, then radiotherapy would appear logical and perhaps useful. If there is bony replacement by tumour, then radiation destruction of this tumour might well accelerate any tendency to vertebral body weakening and collapse. If the neurological compression is due to an actively collapsing vertebra with angulation of the spine, then there would appear to be little justification for radiotherapy as the initial treatment.

Decompression of the compromised spinal cord or cauda equina has usually been achieved by laminectomy. ${ }^{3}$ This will usually provide the diagnosis and may result in some neurological preservation or improvement, but it must render the spine less stable. The greatest likelihood is that this approach will still only allow removal of a part of the tumour, most of which is likely to be anterior and spreading from deposits in the vertebral bodies. ${ }^{5}$

As the main weight bearing of the spine is through the vertebral bodies and as it is this structure that is most commonly the site of malignant deposit, ${ }^{5}$ clearly the most logical surgical approach would be to remove the involved vertebral body and to replace it with a satisfactorily weight bearing substitute. Scoville in $1967,{ }^{10}$ Cross in $1971,{ }^{11}$ Cantu in $1974^{12}$ and Harrington in $1981^{13}$ all used this approach to the problem. A wide exposure allowed radical excision usually with an acrylic vertebral body replacement, strengthened by metal in one form or another. Harrington's 14 cases did uniformly well, with only one fixation failure which was later corrected. The majority of the patients had from one to nearly four years total relief from symptoms of pain and neurological deficit. The procedure itself is formidable, but if it seemed possible to gain such a protracted period following the surgery, then it must be justifiable, at least in selective cases.

We are inclined to expect less in the way of survival from the ravages of the primary disease and would therefore choose a simpler procedure that allows not only histological diagnosis, but decompression and also efficient and relatively easy stabilisation of the spine. 

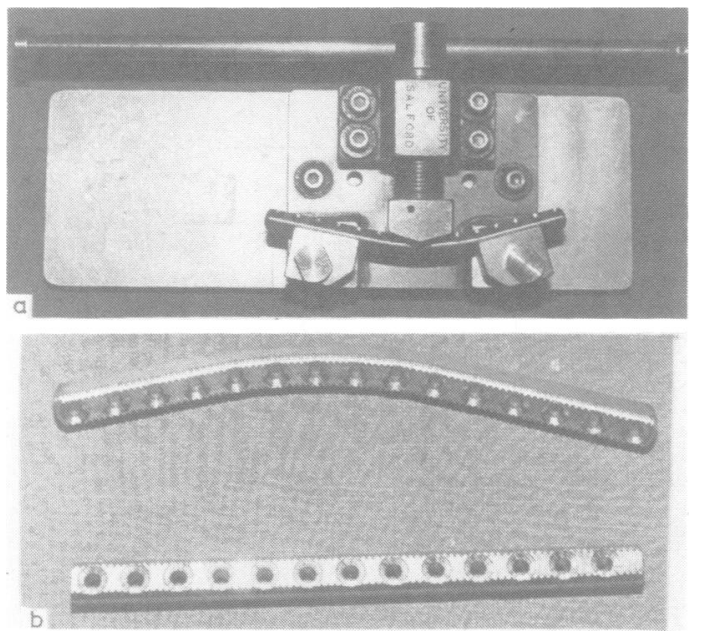

Fig 1 (A) Prototype bending device with rod in place, (B) stainless steel rod, straight and bent.

\section{Method}

A technique for stabilising the spine using the posterior approach has been designed by Banks and Dervin. ${ }^{14}$ A $3 / 8$ inch $(9 \mathrm{~mm})$ square stainless steel rod is formed to the contours and curvatures of the exposed spine, in the operating theatre, using a bending device (fig 1A). The rod is perforated at regular, centimetre, intervals to allow screw fixation to the posterior vertebral arches as illustrated (fig 1B). The screws enter the bone at the base of

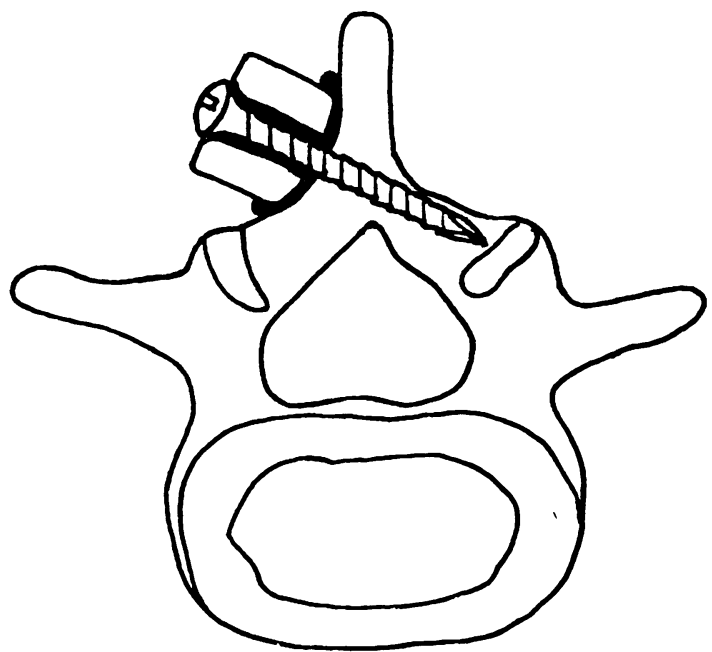

Fig 2 Cross sectional diagram of a vertebra together with stabilising rod to show the line of screw fuxation. the spinal process and progress obliquely across the midline into the opposite lamina (fig 2). The rod is bedded down onto the irregular platform provided by the adjacent laminae and spinous processes, by a thin layer of cyanoacrylate. The rod is firmly screwed home while the cyanoacrylate is still pliable. Additional fixation by wiring through the perforations to the laminae or spinous processes can be performed if necessary. The advantages of this method are:- (1) The intrinsic strength of the rod which requires no additional reinforcing materials, (2) The rod, in conforming to the spinal configuration, is completely unstressed and is therefore unlikely to dislocate. This is to be compared with the use of a Harrington rod which is wedged in place, under stress, and is therefore always likely to spring loose at one end and dislocate, (3) Fixation is achieved immediately adjacent to the point of instability by multiple points of anchorage to uninvolved bone. This is superior to the indirect and distant fixation by hooks or wedges or angulation by other techniques. ${ }^{15-17}$ The acrylic used in this method is small in quantity and serves only to complete the surface conformation of the rod to the underlying bone and is not used to provide strength. It can, however, act as a locking washer on the screws. Its low value modulus of elasticity when compared with bone or steel confers the additional theoretical advantage of its being able to take up transferred forces between these two structures. ${ }^{14}$

\section{Summary of Cases}

This technique has now been used on 23 cases of metastatic malignancy and three cases of primary malignancy of the spine. It has also been used for stabilising three cases of lumbar spondylolisthesis, two cases of thoracic tuberculosis, and in a modified form on two cases of metastatic malignancy when an anterior approach was also used. The results are detailed in the table.

In ten cases the primary cancer was in the breast. There were two prostatic carcinomatoses, two myelomatoses and two melanomatoses. Instabilitty was present at fifteen thoracic, thirteen lumbar and one cervical levels: in five cases instability was present, and treated, at two levels. In all but one patient, pain was prominent in the clinical syndrome and relieved in each. The pain relief lasted to death or to latest follow-up in 22 of the 25 cases, though in several, prior to death, pain had appeared elsewhere in the body by extension of the primary process. In two cases pain returned at to the site of stabilisation. In one of these (Case 18) with metastatic melanoma the pain returned after three months as did the paraparesis, and was clearly associated with massive 
Table Details of clinical cases including the response to stabilisation

\begin{tabular}{|c|c|c|c|c|c|c|c|c|c|c|}
\hline \multirow{2}{*}{$\begin{array}{l}\text { Age } \\
\text { (yr) }\end{array}$} & \multirow[t]{2}{*}{ Sex } & \multirow{2}{*}{$\begin{array}{l}\text { Spinal tumour } \\
\text { (origin) }\end{array}$} & \multicolumn{2}{|c|}{ Pre-operative } & \multirow[t]{2}{*}{ Spinal level } & \multicolumn{3}{|c|}{ Post-operative response } & \multirow[t]{2}{*}{ Length of follow } & \multirow[t]{2}{*}{ Outcome } \\
\hline & & & Pain & Para & & Pain & Para & Duration & & \\
\hline $\begin{array}{l}45 \\
67 \\
76 \\
48 \\
34 \\
35 \\
60 \\
69 \\
72 \\
69 \\
38 \\
62 \\
76 \\
41 \\
53 \\
44 \\
42 \\
45 \\
48 \\
70 \\
70 \\
45 \\
67 \\
72 \\
68\end{array}$ & $\begin{array}{l}\mathbf{F} \\
\mathbf{M} \\
\mathbf{F} \\
\mathbf{F} \\
\mathbf{M} \\
\mathbf{F} \\
\mathbf{F} \\
\mathbf{F} \\
\mathbf{F} \\
\mathbf{F} \\
\mathbf{F} \\
\mathbf{F} \\
\mathbf{M} \\
\mathbf{F} \\
\mathbf{F} \\
\mathbf{F} \\
\mathbf{F} \\
\mathbf{M} \\
\mathbf{F} \\
\mathbf{F} \\
\mathbf{F} \\
\mathbf{F} \\
\mathbf{M} \\
\mathbf{F} \\
\mathbf{F}\end{array}$ & $\begin{array}{l}\text { Breast } \\
\text { Parotid } \\
\text { Uterus } \\
\text { Breast } \\
\text { Chondrosarcoma } \\
\text { Melanoma } \\
\text { Breast } \\
\text { Histiocytoma } \\
\text { Breast } \\
\text { Breast } \\
\text { Breast } \\
\text { Breast } \\
\text { Prostate } \\
\text { Breast } \\
\text { Myeloma } \\
\text { Breast } \\
\text { Breast } \\
\text { Melanoma } \\
\text { Cervix } \\
\text { Colon } \\
\text { Myeloma } \\
\text { Kidney } \\
\text { Prostate } \\
\text { Vagina } \\
\text { Cordoma }\end{array}$ & $\begin{array}{l}+ \\
+ \\
+ \\
+ \\
+ \\
+ \\
+ \\
+ \\
+ \\
+ \\
+ \\
+ \\
+ \\
+ \\
+ \\
+ \\
+ \\
+ \\
+ \\
+ \\
+ \\
+ \\
+\end{array}$ & $\begin{array}{l}+ \\
+ \\
+ \\
+ \\
+ \\
+ \\
+ \\
+ \\
+ \\
+ \\
+ \\
+ \\
+\end{array}$ & $\begin{array}{l}\text { T9-11 } \\
\text { T7 } \\
\text { L3 } \\
\text { T12-L4 } \\
\text { T3 } \\
\text { T11 } \\
\text { L3 } \\
\text { L1 } \\
\text { T7 } \\
\text { T10 } \\
\text { L4 } \\
\text { L3 } \\
\text { T7 } \\
\text { L4 } \\
\text { T11-L3 } \\
\text { T6 } \\
\text { T12-L3 } \\
\text { L3 } \\
\text { T5 } \\
\text { T } \\
\text { T9-L4 } \\
\text { C7 } \\
\text { L4 } \\
\text { T5 } \\
\text { L3 }\end{array}$ & $\begin{array}{l}+ \\
+ \\
+ \\
+ \\
+ \\
+ \\
+ \\
+ \\
+ \\
+ \\
+ \\
+ \\
+ \\
+ \\
+ \\
+ \\
+ \\
+ \\
+ \\
+ \\
+ \\
+ \\
+ \\
+\end{array}$ & $\begin{array}{l}\overline{+} \\
- \\
\overline{+} \\
+ \\
+ \\
+ \\
\overline{+} \\
+ \\
+ \\
+ \\
+\end{array}$ & $\begin{array}{c}2 / 12 \\
4 / y r s \\
2 / 12 \\
2 / 12 \\
14 / 12 \\
6 / 12 \\
15 / 12 \\
8 / 12 \\
7 / 7 \\
7 / 12 \\
10 / 12 \\
3 / 12 \\
6 / 12 \\
6 / 12 \\
5 / 12 \\
4 / 12 \\
4 / 12 \\
2 / 12 \\
5 / 12 \\
3 / 12 \\
9 / 12 \\
3 / 12 \\
3 / 12 \\
3 / 12\end{array}$ & $\begin{array}{c}2 / 12 \\
4 / y r s \\
2 / 12 \\
2 / 12 \\
14 / 12 \\
6 / 12 \\
15 / 12 \\
8 / 12 \\
7 / 7 \\
7 / 12 \\
10 / 12 \\
3 / 12 \\
6 / 12 \\
6 / 12 \\
5 / 12 \\
4 / 12 \\
4 / 12 \\
6 / 12 \\
5 / 12 \\
3 / 12 \\
17 / 12 \\
3 / 12 \\
3 / 12 \\
2 / 12 \\
18 / 12\end{array}$ & $\begin{array}{l}\text { Died } \\
\text { Died } \\
\text { Died } \\
\text { Died } \\
\text { Died } \\
\text { Died } \\
\text { Died } \\
\text { Died } \\
\text { Died } \\
\text { Died } \\
\text { Died } \\
\text { Died } \\
\text { Died } \\
\text { Alive } \\
\text { Alive } \\
\text { Alive } \\
\text { Alive } \\
\text { Died } \\
\text { Died } \\
\text { Died } \\
\text { Died } \\
\text { Died } \\
\text { Died } \\
\text { Died } \\
\text { Alive }\end{array}$ \\
\hline
\end{tabular}

Pain = local radicular. Para $=$ neurological deficit .

Response $+=$ Post-operative pain relief or neurological improvement. Duration of response before relapse.

extension of the tumour locally. There was no evidence of spinal instability (fig 3 ). In the other patient, with cordoma, (Case 25) pain and paraparesis returned after three months. In this case there was evidence of slight, though definite further collapse of the affected vertebral body. This tumour appears to be growing rapidly and has continued to progress in spite of two anterior explorations with attempted vertebral body replacement. This is the only example in the whole series of failure of the rod fully to support the spine. It was noted at the initial stabilisation that the bone was soft and several screws appeared to achieve only moderate impaction. Wires were added in an attempt to improve fixation. This bony softening is likely to relate to the previous recumbancy of the patient who had spent ten months in bed, receiving morphia, prior to referral to us, with a presumptive diagnosis of metastatic carcinomatosis.

Improvement in neurological function was seen in 11 out of the 17 patients with deficit at the time of operation. This was dramatic with conversion from inability to walk to walking unaided in six cases (Cases 2, 5, 7, 18, 19, 25). In most, however, paraparesis returned after months. One patient (Case 24) showed no improvement in paraparesis and did not have pain at presentation.

All patients had radiotherapy to the affected spine either before or after stabilisation.
One patient (Case 8) died one week after surgery from pulmonary embolism. One patient (Case 2) with posterior stabilisation and anterior vertebral body replacement using an acrylic prosthesis died three weeks later with fulminating melaena. She had been on longterm dexamethazone therapy. Two patients (Cases 2 and 8 ) died of myocardial infarction and not of their primary tumour.

\section{Discussion}

The management of malignancy has been in general ineffective and uninspiring. ${ }^{2318}$ When pain is present, radiotherapy is usually the preferred initial treatment. No attempt has been made to prove scientifically that it is indeed superior to stabilisation or stabilisation and radiotherapy combined. On the basis of being the least disturbing option, it is likely to be the first choice. If instability is suggested clinically, with aggravation of pain on weight bearing or movement, then stabilisation should be considered even before radiotherapy.

When neurological deficit results from compression, some relief can be expected by surgical decompression as long as the deficit is not complete and has not evolved too rapidly and has not been present too long. ${ }^{13} 19$

The prime site for metastatic deposits in the spine is the vertebral body and the optimal method of 


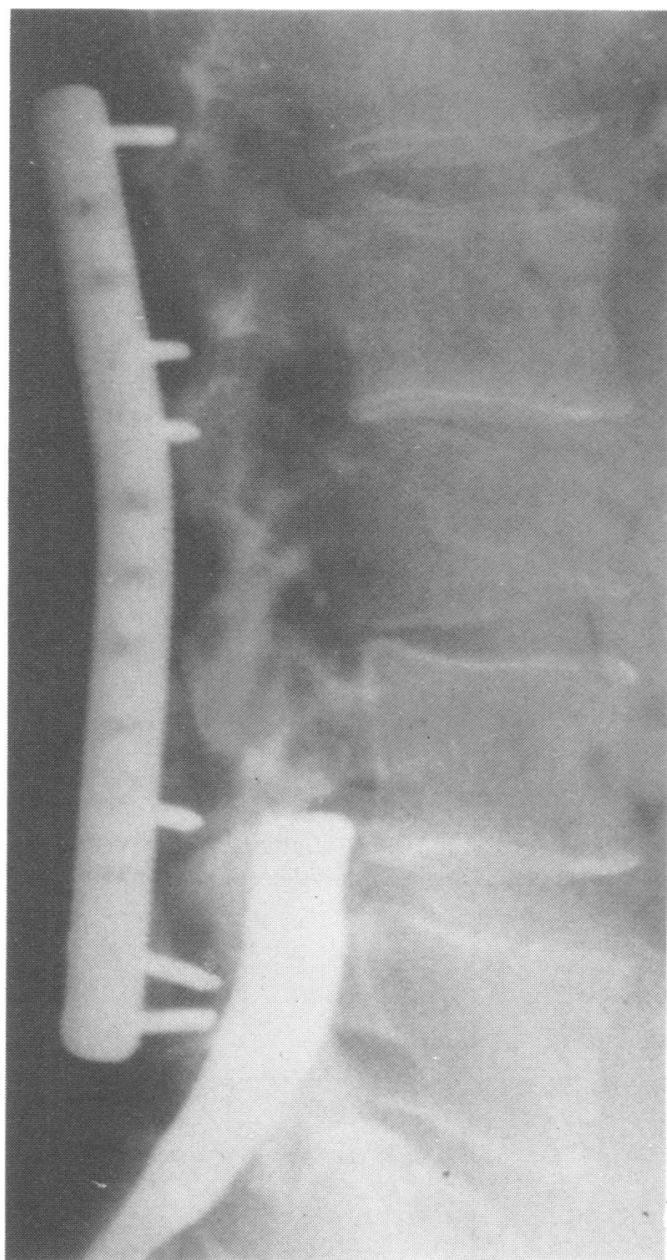

Fig 3 Lumbar stabilisation for third lumbar vertebral body collapse due to melanoma deposit.

decompression and stabilisation should be by vertebral body replacement using an anterior approach.

In the neck, access is easy and fixation to adjacent vertebral bodies should be secure, and this approach is to be recommended. It would seem logical to prop up the space from which the vertebral body has been resected by a prosthesis of either bone, acrylic or a specially constructed appliance (fig 4A \& B).

For vertebral body replacement in the thoracic or lumbar region, a major surgical exploration is required. While Harrington's results would seem totally to justify such a major procedure,,$^{13}$ we think that it must be appropriate to only a small number of selected patients. These would include the fit, young person with perhaps a single vertebral body involved and, more importantly, when there is evidence from the natural history that the primary disease has a relatively indolent course. For the more commonly encountered patient with a relatively rapid story and limited life expectation there would appear to be every justification for adopting a less radical approach.

Posterior exploration with laminectomy limited to the area of compression and with resection of accessible extradural tumour, provides histological verification of the diagnosis and also allows of stabilisation of the effected region by the technique which we have described. Mention has been made of other stabilising techniques and these include the use of Harrington rods and acrylate, by posterior exploration. ${ }^{132021}$ This method can undoubtedly relieve pain. It should be re-stated however that the principle of Harrington rods is that of providing distraction which in engineering terms is not the same as stabilisation. The stressed state of the Harrington rods when their hooks are impacted at a distance from the point of instability must make them liable to rapid dislocation. Case 1 had a Harrington rod inserted at a previous operation which dislocated and required removal. This kind of complication is perhaps particularly likely to occur in a state of carcinomatosis where other bones may be diseased and softened.

The addition of acrylic does not strengthen the rods, nor does it significantly reduce the stress forces. It can however provide the function of a prop when used as a vertebral body replacement and to a certain extent a keying function in suitably excavated cavities, but of course it does not adhere to bone. Positive fixation by a sufficiently strong, but unstressed rod, as described, would appear to be a more logical method of gaining stability.

Laminectomy and extradural decompression alone while providing a diagnosis and perhaps limited neurological improvement is very likely to further de-stabilise the spine. A clear illustration of this was seen in Case 19. This lady had a three months history of mid-thoracic pain, partially relieved by radiotherapy, and a progressive paraparesis over a period of weeks. At the time of transfer she was just unable to stand and had lost posterior column function in the legs. The 5th thoracic vertebral body was already reduced in height (fig 5A). Emergency laminectomy was followed by recovery of motor function such that she could walk with assistance and had return of proprioception. There was also relief of pain while her activity was limited. As we were particularly interested in the problem of instability a radiograph was taken seven days after the operation and this showed further col- 

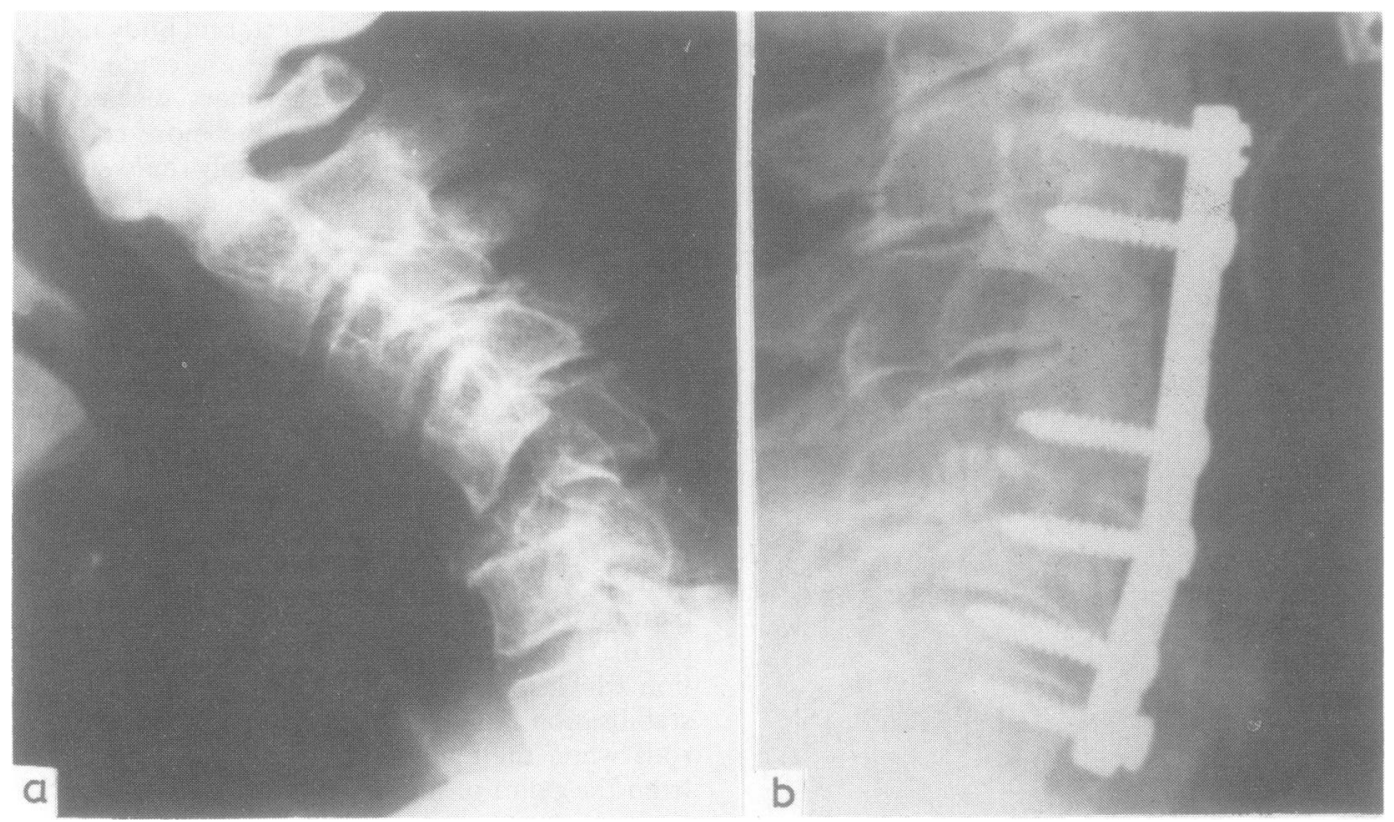

Fig 4 (A) Cervical vertebral body collapse due to metastasis from prostatic carcinoma. (B) Vertebral body resection and replacement with iliac bone graft reinforced by anterior stainless steel bar, screwed into adjacent uninvolved vertebral bodies.
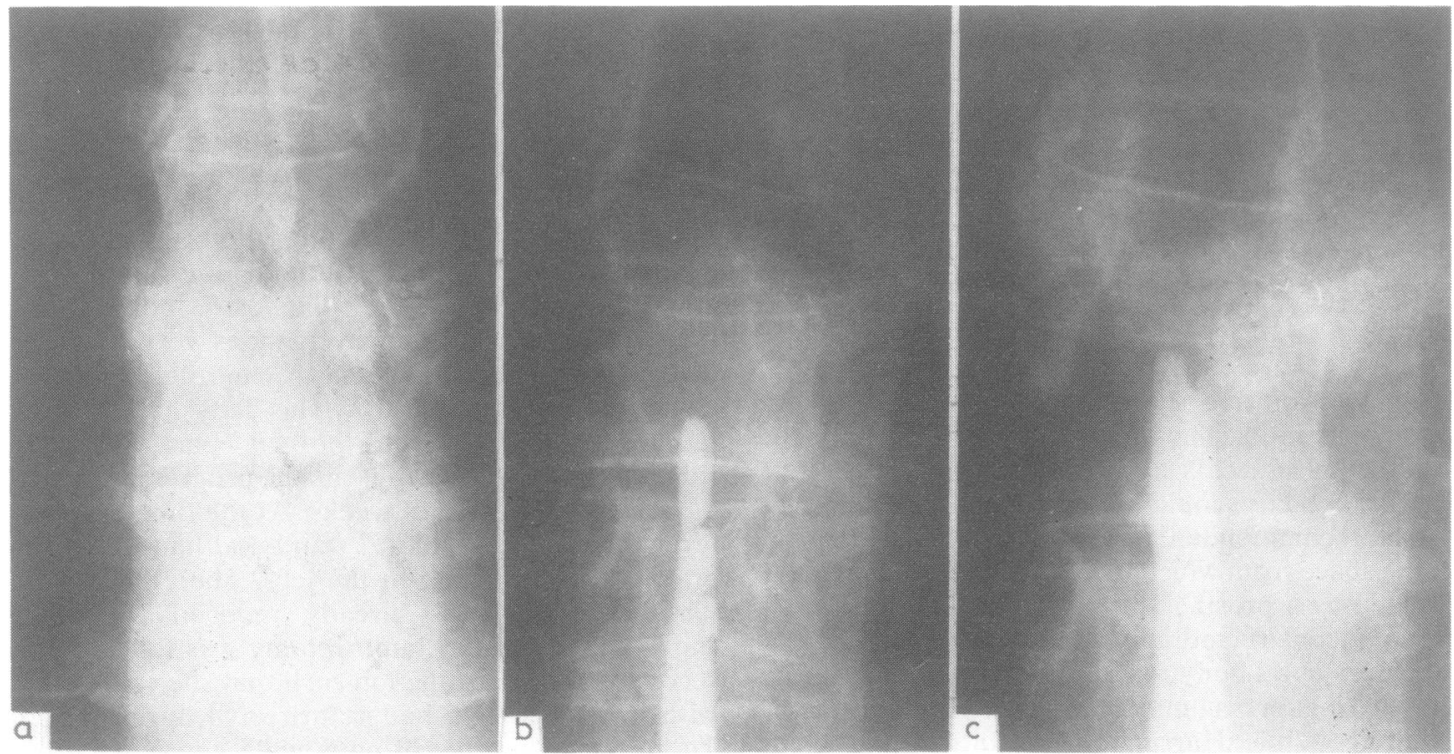

Fig 5 (A) Early osteolytic collapse of the fifth thoracic vertebral body by metastatic carcinoma from the uterine cervix, (B) further collapse twenty-one days after laminectomy. (C) Further collapse twenty-one days after laminectomy associated with severe pain and neurological deterioration. 




Fig 6 Extensive cervical vertebral destruction by metastatic carcinoma from the breast.

lapse of the 5th thoracic vertebral body (fig 5B). On the 21 st day after operation when the patient was about to be discharged home, she experienced several local spinal pain which radiated around the chest. This was associated with regression of her neurological state to that of admission. Major collapse had occurred (fig 5C). Stabilisation was now undertaken and was again followed by recovery of function so that she could walk with a walking aid and when discharged home two weeks later had again recovered posterior column sensation. She remained free from pain until death three months later.

Reduction of vetebral body height indicates at least insipient instability and should be treated appropriately.

Post-operative radiotherapy is completely compatible with the stabilisation technique described. Radiotherapists might well be encouraged to more "curative" regimes of treatment, as described by Harrington, ${ }^{13}$ if stabilisation has been undertaken.

A large number of patients with disseminated carcinomatosis or very advanced local malignancy will not be suitable for this technique. When the general state has advanced so that correction of the local spinal disorder will not effect an improvement in the quality of life, further surgical invasion is inappropriate (fig 6).

Indications for stabilisation are therefore: (1) Clinical instability pain, (2) Radiological instability, (3) Progressive neurological deficit with angulation of the spine, (4) Surgical instability, that is after laminectomy has been undertaken. The last is perhaps the most contentious indication. There would seem to be plenty of personal experience of the validity of this form of instability (Case 19). Gordon Findlay, in this department, has completed a study, as yet unpublished, which unequivocally supports this contention.

Contra-indications for the technique are: (1) When there is no pain and no neurological deficit, (2) When there is no pain and complete neurological deficit, (3) When local disease is too extensive (fig 5), (4) When the general condition precludes surgery.

\section{References}

' Stark RJ, Henson RA, Evans SJW. Spinal metastases: a retrospective survey from a general hospital. Brain 1982; 105: 189-213.

${ }^{2}$ Hensen RA, Urich H. Cancer and the Nervous System. Oxford, (1982).

${ }^{3}$ Brice J, McKissock WS. Surgical treatment of malignant extradural spinal tumours. $\mathrm{Br}$ Med J 1965;1:1341-4

${ }^{4}$ Torma T. Malignant tumours of the spinal extradural space. A study based on 250 histologically verified cases. Acta Chirurg Scand Suppl 1957;225:292-305.

${ }^{5}$ Kakulas BA, Harper CG, Shibasaki K, Bedbrook GM. Vertebral metastases and spinal cord compression. Clin Exp Neurol 1978;15:98-113.

${ }^{\circ}$ Russell DS, Rubinstein LJ. Pathology of Tumours of the Nervous System. London, (1963).

${ }^{7}$ Deshpandi N. In: Persistent Pain Vol. III Lipton S, Miles J eds. London, Academic Press. 1981:34-68.

${ }^{8}$ Calman KC. In: Persistent Pain Vol IV. Lipton S, Miles J ed. London, Academic Press. 1983:103-14.

${ }^{9}$ Bhalla SK. Metastatic disease of the spine. Clin Orthopaed 1970;73:52-60.

${ }^{10}$ Scoville WB, Palmer AH, Samra K, Chong G. The use of acrylic plastic for vertebral replacement or fixation in metastatic disease of the spine. $J$ Neurosurg 1967;27:274-9.

" Cross GO, White HL, White LP. Acrylic prosthesis of the fifth cervical vertebral in multiple myeloma. Technical Note, J Neurosurg 1971;35:112-4.

12 Cantu RC. Anterior spinal fusion using metyl methaacrylate. Int Surg 1974;59:110-1.

${ }^{13}$ Harrington $\mathrm{K}$. The use of methyl-methacrylate for vertebral body replacement and anterior stabilisation of pathological fracture dislocations of the spine due to metastatic malignant disease. J Bone Joint Surg 1981;63A:36-46. 
14 Banks AJ, Dervin E. A simple method for stabilisation of malignant spines. Eng Med 1980;9:81-83.

15 Harrington PR. Treatment of scoliosis corrections and internal fixation by spine instrumentation. $J$ Bone Joint Surg 1962;44A:591-603.

${ }^{16}$ Luque ER, Cardoso A. Segmental corrections of scoliosis with rigid internal fixation. Orthopaed Trans 1977; 1: $136-46$.

17 Allen BL, Ferguson RL. The galveston technique for $\mathrm{L}$ rod instrumentation of the scoliotic spine. Spine 1982;7:276-84.
${ }^{18}$ Northfield DWC. The Surgery of the Central Nervous System. Oxford, Blackwell. (1973).

${ }^{19}$ Hodgeson AR, Stock FE. Anterior spine fusion for the treatment of tuberculosis of the spine. J Bone Joint Surg 1960;42A:295-310.

${ }^{20}$ Galasko CSB, Sylvester BS. Back pain in patients treated for malignant disease. Clin Oncol 1978;4:27383.

${ }^{21}$ Cusick JF, Larson SJ, Walsh PR, Steiner RE. Distraction rod stabilisation in the treatment of metastatic carcinoma. $J$ Neurosurg 1983;59:861-6. 